\title{
Patterns of myocardial fibrosis by CMR in patients with conduction abnormalities
}

\author{
Omar Cheema ${ }^{1,2^{*}}$, Muhammed Umair Qamar ${ }^{2}$, Jiaqiong $\mathrm{Xu}^{2}$, Miguel Quinones ${ }^{2}$, William A Zoghbi ${ }^{2}$, Dipan J Shah ${ }^{2}$ \\ From 15th Annual SCMR Scientific Sessions \\ Orlando, FL, USA. 2-5 February 2012
}

\begin{abstract}
Summary
Cine and DE-CMR performed in a cohort of patients revealed that the presence of $\mathrm{LBBB}$ was more frequently associated with increases in LV volumes and depression in LV function, whereas RBBB or nonspecific conduction delay were more strongly associated with septal replacement fibrosis.
\end{abstract}

\section{Background}

Ventricular conduction delay is thought to occur from a variety of differing mechanism including ischemia or infarction, left ventricular (LV) hypertrophy and/or dilation, and fibrotic degenerative disease of the conduction system. CMR is an ideal modality to evaluate for these mechanisms as cine-CMR is the "gold-standard" for assessment of cardiac morphology and function, and delayed enhancement (DE)-CMR has emerged as a robust modality for assessment of LV replacement fibrosis.

\section{Objective}

To compare the prevalence of abnormalities on cine and DE-CMR in patients with various forms of ventricular conduction delay on 12 lead ECG.

\section{Methods}

We prospectively enrolled 698 consecutive patients presenting to our center from July, 2009 to March, 2010 for CMR for a variety of clinical indications. Patients were categorized based on QRS morphology on concurrent 12-lead ECG tracings into the following 4 groups: 1) no conduction delay (QRS duration $\leq 100 \mathrm{msec}$ ); 2) nonspecific conduction delay (NSCD) [QRS duration more than 100 but less than $120 \mathrm{msec}$; 3) LBBB (QRS

\footnotetext{
'Division of Cardiology, University of Texas Medical Branch, Galveston, TX,
} USA

Full list of author information is available at the end of the article duration $\geq 120$ msec with LBBB morphology by Minnesota code); and 4) right bundle branch block (RBBB) [QRS duration $\geq 120$ with RBBB morphology by Minnesota code]. Cine and DE-CMR images were analyzed for left atrial (LA) volumes, LV and right ventricular (RV) volumes and ejection fraction (EF), LV mass, and LV replacement fibrosis per standard methodologies for our laboratory.

\section{Results}

The baseline clinical characteristics of our cohort included cardiac risk factors of hypertension in 401 (57\%); diabetes in 182 (25\%); hyperlipidemia in 310 (44\%); and tobacco abuse in 57 (8\%). Symptoms of chest pain were present in 170 (25\%) and dyspnea in 289 (41\%). Prior history of myocardial infarction was present in 94 (13\%). The systolic blood pressure was $127 \mathrm{mmHg}$ \pm 21 ; diastolic blood pressure was $72 \mathrm{mmHg} \pm 12$; the body surface area was $1.94 \mathrm{~kg} / \mathrm{m}^{2} \pm 0.27$; heart rate was $75 \mathrm{bpm} \pm 14$; and LVEF $57 \% \pm 17$. Imaging characteristics as segregated based on the QRS complex are shown in Table 1. Note that patients with LBBB had increased LV volumes, and reduced LVEF compared to all other groups. Interestingly total LV fibrosis (as \% of LV) or septal location fibrosis was not different between LBBB patients and the other groups. However patients with RBBB or NSCD had a greater proportion of septal fibrosis and the latter also had a greater total LV fibrosis extent.

\section{Conclusions}

RBBB or NSCD are more strongly associated with septal replacement fibrosis whereas $\mathrm{LBBB}$ is more frequently associated with increases in LV volumes and depression in LV function. 
Table 1

\begin{tabular}{|c|c|c|c|c|}
\hline Variable & LBBB $(n=22)$ & RBBB $(n-40)$ & $\operatorname{NSCD}(n=113)$ & No Delay $(n=523)$ \\
\hline LA Volume (ml) & $133 \pm 53.5$ & $118 \pm 63.4$ & $121 \pm 46.3^{a}$ & $105 \pm 43.7$ \\
\hline LVEDV (ml) & $231 \pm 109^{b, c, d}$ & $139 \pm 59^{e}$ & $179 \pm 71$ & $141 \pm 60$ \\
\hline LVESV (ml) & $162 \pm 97^{b, c, d}$ & $65 \pm 47$ & $93 \pm 68^{a}$ & $64 \pm 54$ \\
\hline LV Myocardial Mass (g) & $176 \pm 75$ & $154 \pm 59$ & $177 \pm 65^{a}$ & $146 \pm 60$ \\
\hline LVEF (\%) & $35.4 \pm 17.6^{\mathrm{b}, c, \mathrm{~d}}$ & $56.7 \pm 14.1$ & $52.8 \pm 19.8^{\mathrm{a}}$ & $59.1 \pm 16.8$ \\
\hline RVEDV (ml) & $130 \pm 60$ & $161 \pm 79^{f}$ & $144 \pm 53$ & $130 \pm 60$ \\
\hline $\operatorname{RVESV}(\mathrm{ml})$ & $75 \pm 62$ & $90 \pm 62^{f}$ & $74 \pm 45$ & $63 \pm 33$ \\
\hline RVEF (\%) & $49.0 \pm 18.4$ & $47.1 \pm 10.8$ & $50.7 \pm 13.8$ & $53.0 \pm 12.1$ \\
\hline Scar Extent (\% of LV) & $4.3 \pm 7.1$ & $5.5 \pm 8.7$ & $7.7 \pm 12.6^{\mathrm{a}}$ & $4.1 \pm 9.2$ \\
\hline Septal Location Fibrosis & $3(13.6)$ & $10(25.0)^{f}$ & $31(27.4)^{a}$ & $35(6.7)$ \\
\hline
\end{tabular}

Data are presented as mean \pm SD for continuous variables and number (\%) for categorical variables. P-values are based on one-way analysis of variance (ANOVA) with Bonferroni correction for multiple pairwise comparisons for continuous variables and Fisher's exact test for categorical variables. ${ }^{a} \mathrm{P}<0.05$ for comparison between NSCD and normal ${ }^{b} \mathrm{P}<0.05$ for comparison between LBBB and normal ${ }^{c} \mathrm{P}<0.05$ for comparison between $L B B B$ and NSCD ${ }^{\mathrm{d}} \mathrm{P}<0.05$ for comparison between $L B B B$ and $\mathrm{RBBB}{ }^{\mathrm{e}} \mathrm{P}<0.05$ for comparison between $\mathrm{RBBB}$ and $\mathrm{NSCD}{ }^{\mathrm{f}} \mathrm{P}<0.05$ for comparison between $\mathrm{RBBB}$ and normal

\section{Funding}

None.

\section{Author details}

'Division of Cardiology, University of Texas Medical Branch, Galveston, TX USA. ${ }^{2}$ Cardiology, Methodist DeBakey Heart \& Vascular Center, Houston, TX, USA.

Published: 1 February 2012

\section{Submit your next manuscript to BioMed Central} and take full advantage of:

- Convenient online submission

- Thorough peer review

- No space constraints or color figure charges

- Immediate publication on acceptance

- Inclusion in PubMed, CAS, Scopus and Google Scholar

- Research which is freely available for redistribution

Submit your manuscript at www.biomedcentral.com/submit
Biomed Central 